\title{
Structural changes during the natural aging process of InN quantum dots
}

Cite as: J. Appl. Phys. 105, 013527 (2009); https://doi.org/10.1063/1.3010309

Submitted: 09 July 2008. Accepted: 18 September 2008. Published Online: 09 January 2009

D. González, J. G. Lozano, M. Herrera, N. D. Browning, S. Ruffenach, O. Briot, R. García, et al.

\section{ARTICLES YOU MAY BE INTERESTED IN}

Indium nitride (InN): A review on growth, characterization, and properties

Journal of Applied Physics 94, 2779 (2003); https://doi.org/10.1063/1.1595135

When group-III nitrides go infrared: New properties and perspectives

Journal of Applied Physics 106, 011101 (2009); https://doi.org/10.1063/1.3155798

Indium nitride quantum dots grown by metalorganic vapor phase epitaxy

Applied Physics Letters 83, 2919 (2003); https://doi.org/10.1063/1.1613044

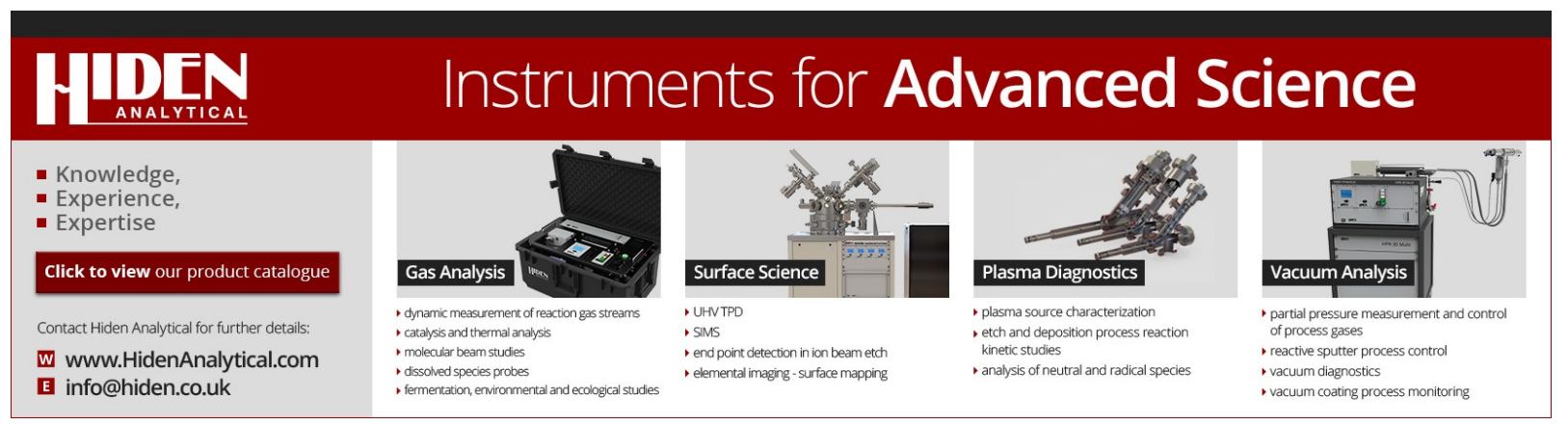




\title{
Structural changes during the natural aging process of InN quantum dots
}

\author{
D. González, ${ }^{1, a)}$ J. G. Lozano, ${ }^{1}$ M. Herrera, ${ }^{2}$ N. D. Browning, ${ }^{2,3}$ S. Ruffenach, ${ }^{4}$ O. Briot, ${ }^{4}$ \\ and R. García ${ }^{1}$ \\ ${ }^{1}$ Departamento de Ciencia de los Materiales e IM y QI, Universidad de Cádiz, Apdo. 40, E-11510 Puerto \\ Real (Cádiz), Spain \\ ${ }^{2}$ Department of Chemical Engineering and Materials Science, University of California-Davis, One Shields \\ Ave., Davis, California 95616, USA \\ ${ }^{3}$ Chemistry, Materials and Life Sciences Directorate, Lawrence Livermore National Laboratory, 7000 East \\ Avenue, Livermore, California 94550, USA \\ ${ }^{4}$ Groupe d'Etudes des Semiconducteurs, UMR 5650 CNRS, Place Eugène Bataillon, Université Montpellier \\ II, 34095 Montpellier, France
}

(Received 9 July 2008; accepted 18 September 2008; published online 9 January 2009)

\begin{abstract}
The natural aging process of InN nanostructures by the formation of indium oxides is examined by transmission electron microscopy related techniques. Uncapped and GaN-capped InN quantum dots (QDs) on GaN/sapphire substrates were grown under the same conditions and kept at room temperature/pressure conditions. The GaN capping layer is found to preserve the InN QDs in the wurtzite phase, avoiding the formation of group-III oxides, while in the uncapped sample, a thin layer of cubic phases are formed that envelops the nucleus of wurtzite InN. These cubic phases are shown to be mainly bcc- $\operatorname{In}_{2} \mathrm{O}_{3}$ for long aged samples where the nitrogen atoms in the InN surface layers have been substituted by atmospheric oxygen. This process implies the gradual transformation of the In sublattice from hcp to a quasi-fcc structure. Metastable zinc-blende InN phases rich in oxygen atoms are proposed to act as intermediate phases and they are evinced in samples less aged. The large concurrence of interplanar spaces, the twin formation, and the existence of a free surface that facilitates the transformation support this mechanism and would explain the high instability of the InN nanostructures at ambient conditions. (C) 2009 American Institute of Physics. [DOI: 10.1063/1.3010309]
\end{abstract}

\section{INTRODUCTION}

The past decade has seen the evolution and rise of IIInitride semiconductors for optoelectronic applications. Although $\mathrm{InN}$ is the latest to be developed, it is a key material for extending the photonic applications to the infrared range of III-N based optoelectronic devices and to high power/ temperature electronics, due to its superior transport characteristics. In spite of its promising properties, it is up to now the least understood of the III-nitride semiconductors. ${ }^{1}$ The reason for this is that the growth of $\mathrm{InN}$ is the most difficult among the III-nitrides because the low InN dissociation temperature and high equilibrium $\mathrm{N}_{2}$ vapor pressure requires a low growth temperature. ${ }^{2}$ Mostly thanks to improved growth methods, high quality InN films have now become available, revealing surprising properties such as the true $0.62 \mathrm{eV}$ room temperature band gap energy of InN. ${ }^{3,4}$ Another important discovery about wurtzite $\mathrm{InN}$ is its very strong surface charge accumulation on the order of $10^{13} \mathrm{~cm}^{-2}$. The accumulated electrons, which stay within $4 \mathrm{~nm}$ from the top $\mathrm{InN}$ surface, can be modulated by external treatments contributing considerably to the lateral conductivity of thin InN films. Recently reported results reveal the promising applications of InN epilayers for chemical and biological sensor. ${ }^{6,7}$ Additionally, the growth of InN quantum dots (QDs) is the next challenge, where the control of their dimensions, their surface density, and their positions could permit the emission

${ }^{a)}$ Electronic mail: david.gonzalez@uca.es. wavelength to be tuned for a larger band gap that would cover the actual telecommunication spectra and the design of specific devices as single photon emitters or detectors. ${ }^{8-10}$

In the understanding of the properties of $\mathrm{InN}$, oxygen has played and still plays an important role because it is a major probable candidate for the residual donor species ${ }^{11}$ and also a possible responsible for the variations in the band gap of InN reported in the bibliography. ${ }^{12}$ For the latter, the formation of a crystalline semiconducting $\mathrm{InN}-\mathrm{In}_{2} \mathrm{O}_{3}$ alloy phase $^{12}$ or even amorphous oxynitrides and hydroxides phases have been suggested, ${ }^{13,14}$ but there is no direct physical evidence for these phases reported in the literature. Very recently, the formation of oxide precipitates in $\mathrm{InN}$ films has been reported, but in all cases, it has been assumed that the oxidation process occurs during the growth at high temperature due to high level of oxygen contamination in the growth chamber. ${ }^{15,16}$ In any case, the InN surface as usual naturally forms a thin native oxide layer of physiabsorbed oxygen under ambient conditions, being an important factor but not the only one to explain the broadening of band gap values observed in the literature. ${ }^{17}$ In this work, we show the aging process of InN QDs due to atmospheric exposure, which takes place likely through the chemiabsorption process of oxygen atoms into the InN. The comparison between uncapped and GaN capped InN QDs shows the phase transformations that take place under room temperature/pressure conditions, where the original wurtzite structure changes to cubic phases by means of the chemical incorporation of oxygen. 




FIG. 1. HAADF image of the 36 month old capped sample B taken along the $[11 \overline{2} 0]$ pole. The GaN capping layer envelops totally the $\mathrm{InN}-\mathrm{w}$ QD without intermixing between III elements.

\section{EXPERIMENTAL DETAILS}

Several InN QDs samples were grown on $\mathrm{GaN} / \mathrm{Al}_{2} \mathrm{O}_{3}$ by metal-organic vapor phase epitaxy, where a buffer layer of GaN was grown on (0001) sapphire wafer using the usual process at a temperature close to $1000{ }^{\circ} \mathrm{C}$ in all cases. The temperature was then lowered to $550^{\circ} \mathrm{C}$ and InN QDs were deposited using trimethylindium (TMIn) and ammonia $\left(\mathrm{NH}_{3}\right)$ as precursors. Samples A and B were grown 36 months ago and maintained under room temperature and pressure conditions. Both samples were grown using a V/III ratio of 15000 to obtain an average height of $12 \pm 2 \mathrm{~nm}$. For sample $\mathrm{B}$, a capping layer of $\mathrm{GaN}$ was deposited at low temperature $\left(550^{\circ} \mathrm{C}\right)$ in order to cover the dots and to prevent their decomposition at higher temperature resulting in a $20 \mathrm{~nm}$ thick single crystal. Sample C is an uncapped $\mathrm{InN}$ QDs structure grown 12 months ago. These InN dots were grown from TMIn and $\mathrm{NH}_{3}$ under a V/III molar ratio of 5000 at $550{ }^{\circ} \mathrm{C}$, in order to maximize the areal density. The dot height is around $12 \mathrm{~nm}$. Conventional and high resolution transmission electron microscopy (HRTEM), as well as high angle annular dark field (HAADF) and electron energy loss spectroscopy (EELS) in scanning mode were carried out in cross section geometry samples using JEOL 2010F and JEOL JEM 2500SE microscopes, both working at $200 \mathrm{kV}$.

\section{RESULTS AND DISCUSSION}

In the elder samples A and B, InN QDs show a welldefined flat hexagonal shape with an average height around $12 \mathrm{~nm}$. A complete characterization of the morphology of these QDs can be found elsewhere. ${ }^{18,19}$ HAADF analysis of the capped sample B confirmed clearly that the InN QDs were covered completely by the GaN layer and no interdiffusion between In and Ga had taken place (Fig. 1). The In atoms are confined into the QDs and the GaN layer acts as a continuous layer avoiding the exposure of the $\mathrm{InN}$ to the atmosphere. In order to analyze the phases coexisting inside the QD, HRTEM micrographs from the sample B in cross section orientation were taken along the $[11 \overline{2} 0]$ axis [Fig. 2(a)]. The Fig. 2(b) illustrates a fast Fourier transform (FFT) of the image using the DIGITAL MICROGRAPH ${ }^{\circledR}$ software. The spots in the FFT image correspond to a diffraction pattern of

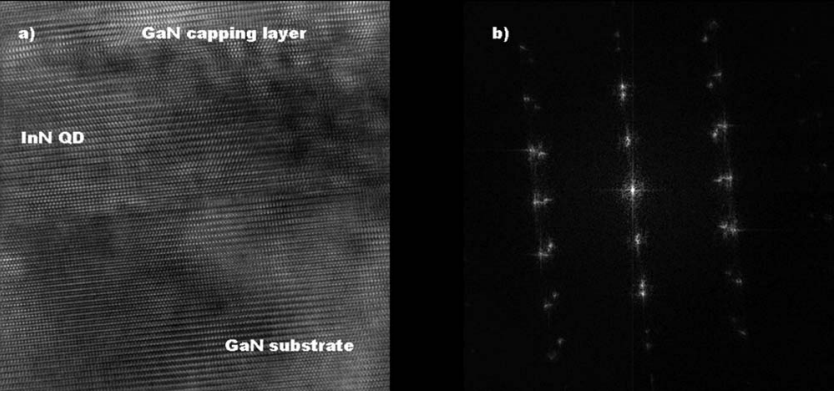


the 36 month old capped sample B. (b) FFT image shows the characteristic wurtzite patterns for $\mathrm{GaN}$ and $\mathrm{InN}$ at this pole and no cubic phases are present for both compounds.

wurtzite structures of $\mathrm{GaN}-\mathrm{w}$ and $\mathrm{InN}-\mathrm{w}$ in the $[11 \overline{2} 0]$ zone axis. It is remarkable that the sample does not contain any appreciable volume of cubic phases and oxide phases in the $\mathrm{GaN}$ or InN regions. The (0001) planes follow a stacking sequence of the hexagonal structure, namely $A B A B$, in all the QDs studied and we have not been able to distinguish any change in the structure after the last 36 months.

Figure 3(a) corresponds to a HRTEM image taken 36 month ago in the $[11 \overline{2} 0]$ zone axis of sample A, namely without the capping layer. The sample was studied shortly after its growth, and it shows a FFT pattern [see Fig. 3(b)] similar to the elder sample B, that is to say, only the wurtzite phases are present. Figure 4 illustrates a HRTEM image of the same sample taken recently, i.e., 36 months after its growth. We can easily note differences of the stacking sequence in some regions of the QD where a characteristic $A B C A B C$ sequence likely belonging to cubic phases is observed. The FFT of the image [Fig. 5(a)] shows, together with the distinctive spot configuration of the wurtzite phases in the $\langle 11 \overline{2} 0\rangle$ orientation, the appearance of spot patterns that could correspond to the zinc-blende polytype in the $\langle 110\rangle$ orientation. The cubic phase comes into view as two patterns with the same (111) indexed spots but different orientation in reciprocal space, namely $[1 \overline{1} 0]$ and $[\overline{1} 10]$. The in-plane relationships between the two InN phases are $\operatorname{InN}-z b(111) \| \operatorname{InN}-\mathrm{w}(0002) \quad$ and $\quad \operatorname{InN}-\mathrm{zb}[1 \overline{1} 0]$ $\times[110] \| \mathrm{InN}-\mathrm{w}[11 \overline{2} 0]$. This highlights the coincidence of the indexed spots (111) of zinc-blende phases with the (0002) spot of the wurtzite phase that evidences of a very similar interplanar spacing between the $A B C A B C$ stacking sequence

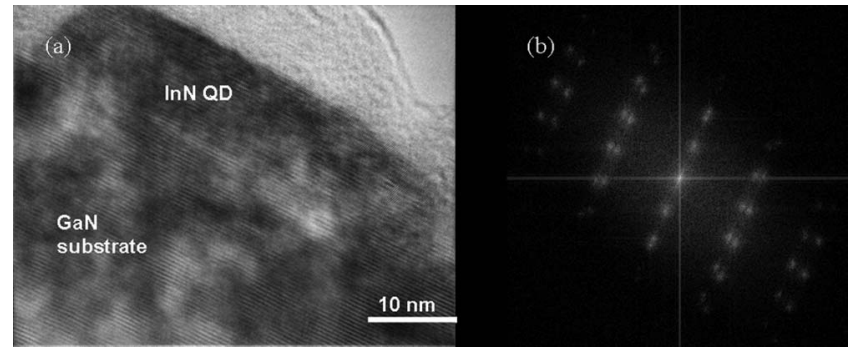

FIG. 3. (a) Cross sectional HRTEM image of the uncapped sample A taken along the $[11 \overline{2} 0]$ pole shortly after its growth. (b) The FFT image shows only the characteristic wurtzite patterns for $\mathrm{GaN}$ and $\mathrm{InN}$ for this pole. 


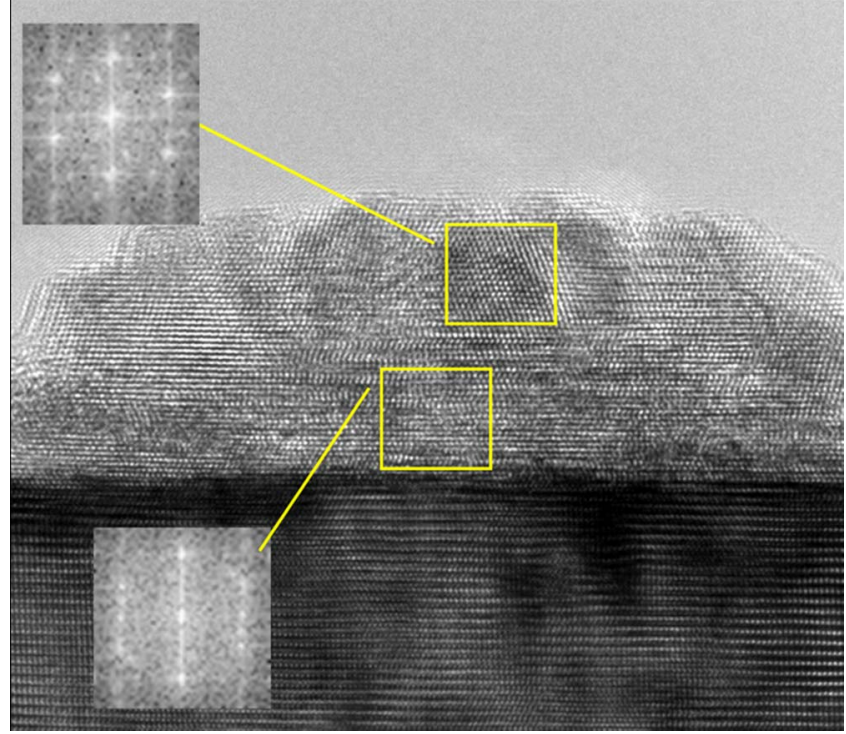

FIG. 4. (Color online) X-HRTEM micrograph of 36 month old uncapped sample A taken along the $[11 \overline{2} 0]$ pole. The insets show FFT images of two different regions of the image.

of the cubic phase and the $A B A B$ stacking sequence of the hexagonal phase. ${ }^{20}$ The original wurtzite phase would have changed to zinc-blende phase by the alteration of the close packed stacking sequence. However, the phase transition to cubic phase occurs forming two FFT patterns that can be obtained by a simple rotation of $180^{\circ}$ about the [111] axis that acts as a twin axis. We must highlight that the FFT shows extra spots that we cannot identify with other InN orientations or phases. These additional spots could be attributed to formation of oxide precipitates.

To analyze these precipitates, we have used the EMS software to create the diffraction patterns of $\operatorname{In}_{2} \mathrm{O}_{3}$ in different orientations. The stable phase of $\operatorname{In}_{2} \mathrm{O}_{3}$ has a $\mathrm{CaF}_{2}$ cubic structure called bixbyite with the space group $I a \overline{3}$, having a complex unit cell which contains 80 atoms. Figure 5(b) draws into the FFT images the theoretical diffraction pattern of the cubic oxide polytype plotting the corresponding spots as hollow circles with sizes proportional to the intensity. The extra spots in the FFT can be explained by the formation of two rotated crystals of bcc- $\operatorname{In}_{2} \mathrm{O}_{3}$ both oriented along the $\langle 110\rangle$ poles. Thus, the $\operatorname{In}_{2} \mathrm{O}_{3}$ crystal associated with green circle pattern has a reticular relationship with the $\mathrm{InN}-\mathrm{w}$ taken as reference of $\operatorname{In}_{2} \mathrm{O}_{3}(2 \overline{2} 2) \| \operatorname{InN}-\mathrm{w}(0002)$ and $\mathrm{In}_{2} \mathrm{O}_{3}[\overline{2} 20] \| \operatorname{InN}-\mathrm{w}[11 \overline{2} 0]$. The pattern constituted by the red circles is a mirror image of the green pattern achieved by a rotation of $180^{\circ}$ about the growth direction. To confirm the identification, the lattice parameter was estimated from the FFT images using relaxed $\mathrm{GaN}$ as a reference. The measured value of 10.1(3) $\AA$, is in a good agreement with previously reported $\mathrm{In}_{2} \mathrm{O}_{3}$ lattice parameter of $10.1192 \AA \AA^{21}$ We can exclude the possibility that $\operatorname{In}_{2} \mathrm{O}_{3}$ phases were introduced during mechanical preparation of the TEM specimen, since in all $\mathrm{InN}$ samples studied shortly after their growth, the spots characteristics of oxide phases do not appear (Fig. 3).

In order to obtain quantitative information about the proportion of $\mathrm{In}_{2} \mathrm{O}_{3}$ and $\mathrm{InN}-\mathrm{zb}$ in the cubic regions, we have

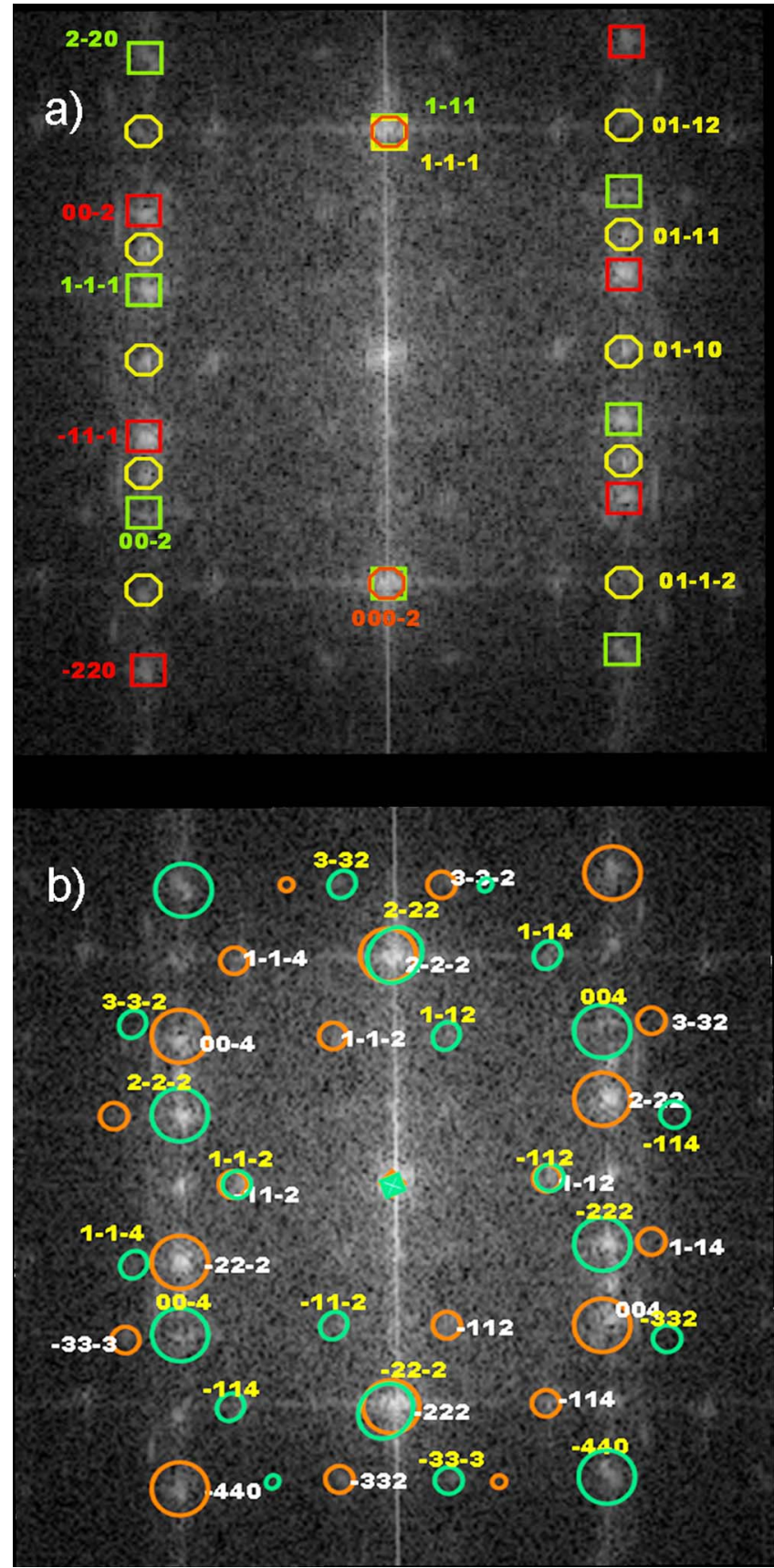

FIG. 5. (Color online) (a) FFT image showing the diffractogram of the InN phases: InN-w (yellow triangles) and $\mathrm{InN}-\mathrm{zb}$ (green and red squares) (b) FFT image showing the diffractogram of the $\operatorname{In}_{2} \mathrm{O}_{3}$ crystals. The sizes of circles are proportional at the intensity from the electron diffraction simulation using the EMS software.

calculated the relative kinematical intensity of the spots for a diffraction pattern of an $\operatorname{In}_{2} \mathrm{O}_{3}$ crystal under the same crystallographic and microscopy conditions (using the EMS software). The amplitude of the diffused spherical wave for kinematical diffraction is proportional to the Fourier transform of the atomic potential of the sample, although we must be very careful with these results due to the broadening of the atomic potential by thermal vibrations of the atoms, by disorder of the atoms around their lattice and even by the crystal size effect. Taking into account all these considerations, the comparison between the experimental and theoretical relationship of $I_{222} / I_{114}$ in local FFT images suggests a majority 

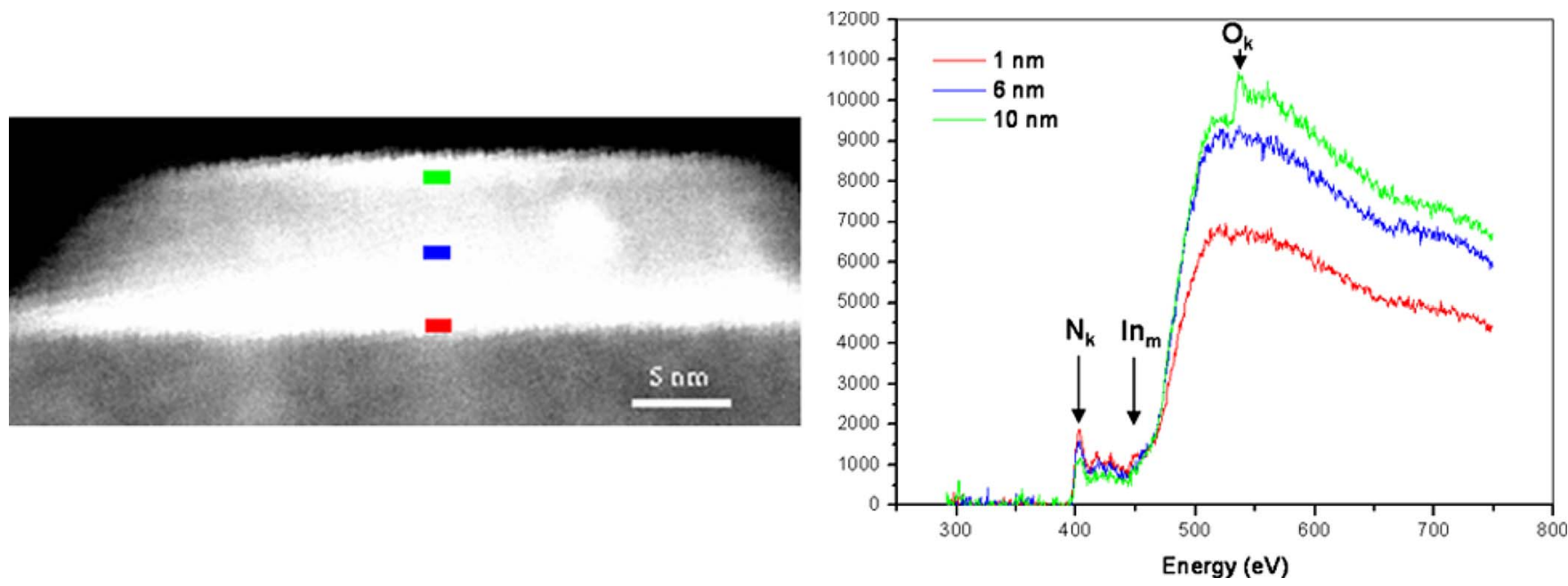

FIG. 6. (Color online) Core loss EELS spectra of an uncapped InN QD collected along the $z$-axis taking as reference the interface InN/GaN.

contribution of the $\operatorname{In}_{2} \mathrm{O}_{3}$ crystals at the common reciprocal lattice spot for the cubic crystals when we approach the surface (see Fig. 4). In order to confirm this data, we have taken a series of core loss EEL spectra along the [0001] axis of the uncapped QD from the interface to the surface. Figure 6 displays the $K$ edge for nitrogen $(401 \mathrm{eV}), M_{4,5}$ edges for indium $(451 \mathrm{eV})$ and $K$ edge for oxygen $(532 \mathrm{eV})$ for three different spatial positions. We can observe the decay of the nitrogen edge as well as the raise of the oxygen edge when approaching the surface and this fact implies the progressive substitution of nitrogen atoms by oxygen as we move toward the surface.

From the earlier work of Foley and Lyngdal, ${ }^{22}$ several authors pointed at the first stage of oxidation is the formation of a type of In-N-O complex. Motlan et al. ${ }^{23}$ who observed a shift to higher optical band gap due to sample aging, proposed aged InN films contained an increasing proportion of an oxygen rich phase characterized by a higher band gap. Kurimoto et al. ${ }^{24}$ using Raman scattering and x-ray diffraction, suggested that InN aged samples consist at the beginning of a mixing of InN:O (InN heavily doped with oxygen) and $\operatorname{In}_{2} \mathrm{O}_{3}$ phases and finally is completed with totally changing into $\operatorname{In}_{2} \mathrm{O}_{3}$. We have performed similar studies for fresher samples and the results show the same trend with a decreased of the amount of oxygen. This is the case of sample C (Fig. 7), an uncapped InN QDs structure kept at room condition during a year where there is a change at the surface of the wurtzite InN polytype to cubic phases, although neither of the weak spots characteristics for the $\operatorname{In}_{2} \mathrm{O}_{3}$ phase appear and only the common spots of the $\mathrm{InN}-\mathrm{zb}$ and $\mathrm{In}_{2} \mathrm{O}_{3}$ are visible. Similar results are observed for comparable aged samples. The formation of an intermediate phase of InN-zb:O highly doped with oxygen could be the reason. Between the lonely wurtzite patterns found in the newer samples and the $\mathrm{InN}-\mathrm{w} / \mathrm{In}_{2} \mathrm{O}_{3}$ patterns in the elder samples, the intermediate aged samples always show both wurtzite and zinc-blende patterns. True origin of this is mainly due to the change of indium sublattice since the atomic scattering factor for electron diffraction increases with $Z$. Figure 8 shows the atomic configurations of the three different crystals oriented in the same direction of the TEM zone axis. The green, red, and cyan spheres correspond to the indium, nitrogen, and oxygen atoms, respectively. The lines do not have a correspondence with the bonds between indium and nonmetallic elements, but they link the indium atoms themselves to describe their stacking sequence. $\mathrm{In}_{2} \mathrm{O}_{3}$ has a bcc-related C-type rare-earth structure where the cation $\mathrm{In}^{+3}$ sublattice forms a quasi-fcc structure. If we ignore the anions, we can consider that the In monolayers suffer a phase transition from the hcp of the $\mathrm{InN}-\mathrm{w}$ to quasi-fcc structure in $\operatorname{In}_{2} \mathrm{O}_{3}$. The process of this transformation can usually be described by homogeneous shear of every pair of hexagonal planes along the [1100] hcp directions, which transforms the hcp structure with $A B A B$ stacking into the fcc phase with $A B C A B C$ stacking along the [111] direction. The driving force for this transformation is the huge difference between the formation enthalpy of $\mathrm{InN}-\mathrm{w}$ $(-31.5 \mathrm{kcal} / \mathrm{mol})$ (Ref. 25) and $\operatorname{In}_{2} \mathrm{O}_{3}(-221 \mathrm{kcal} / \mathrm{mol})$ (Ref. 26) that induces the chemical absorption of oxygen atoms $^{23}$ from the surface and the small difference with the InN-zb phase $(-6.1 \mathrm{kcal} / \mathrm{mol}) .{ }^{27}$ The large concurrence among all the interplanar spaces, the formation of twins, and the free surface contribute to overcome the geometrical constrictions. Thus, the progressive incorporation of oxygen atoms together with the low activation energy for $\mathrm{N}$ desorption ${ }^{28}$ promotes the configuration of metastable oxygen rich zinc-blende phases where indium sublattice follows

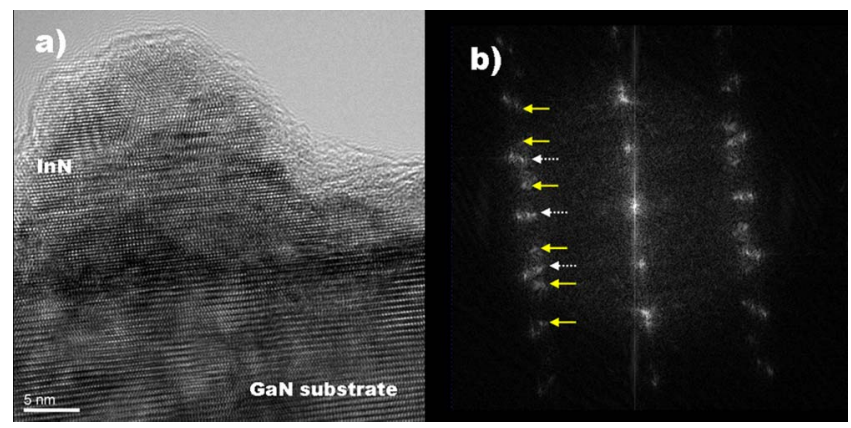

FIG. 7. (Color online) (a) X-HRTEM micrograph of 12 month old uncapped sample $\mathrm{C}$ taken along the $[11 \overline{2} 0]$ pole. (b) FFT pattern where only InN phases appear (solid lines point at InN-zb spots and dashed lines at InN-w spots). 

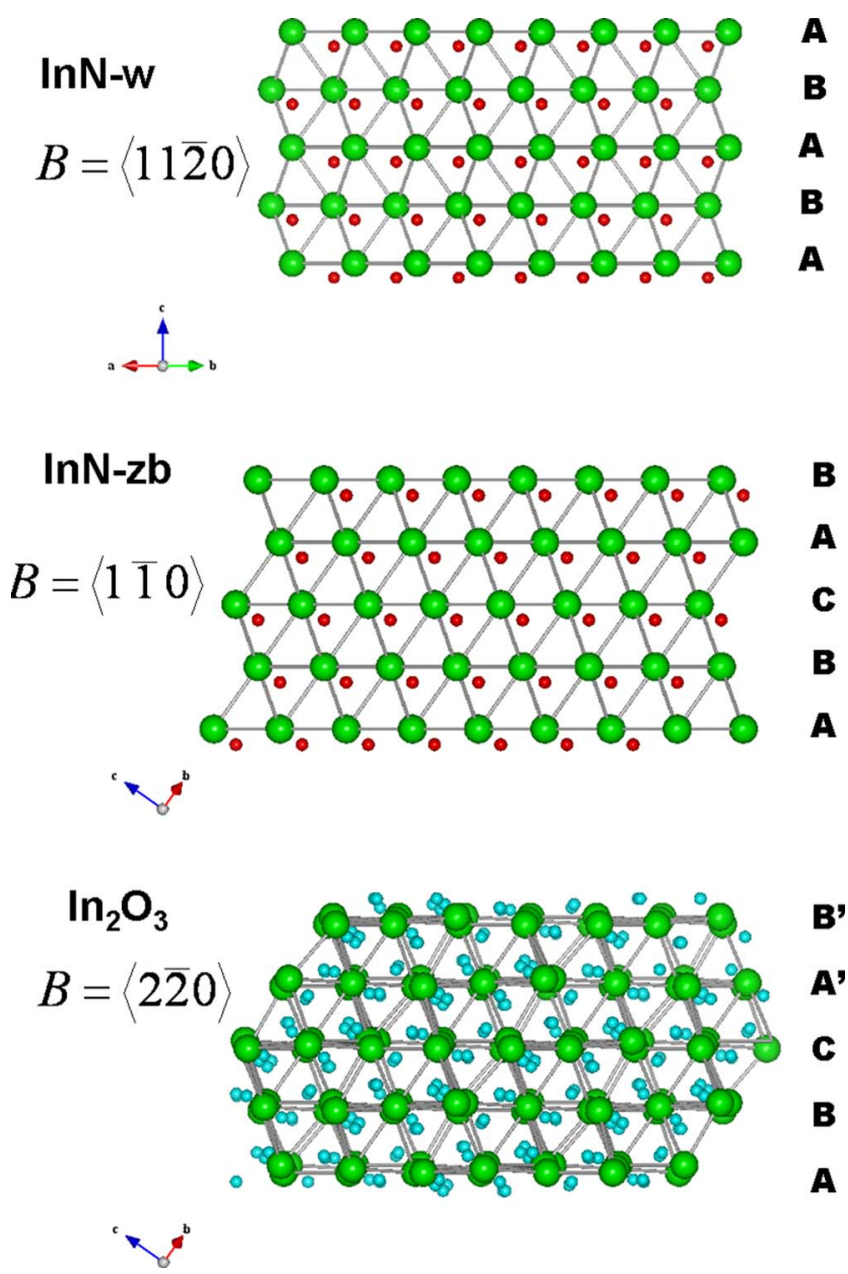

FIG. 8. (Color online) Schematic models of the InN-w, InN-zb and $\operatorname{In}_{2} \mathrm{O}_{3}$ crystals oriented at the same direction of electron beam in the XHRTEM images. The figure shows the stacking sequences of the Indium sublattices (green atoms) in the $\mathrm{InN}$ phases ( $\mathrm{N}$ are red atoms) and $\mathrm{In}_{2} \mathrm{O}_{3}$ (oxygen are blue atoms)

a perfect wurtzite symmetry, giving place finally to the formation of the thermodynamically stable phase, $\operatorname{In}_{2} \mathrm{O}_{3}$, where the indium sublattice suffers a loss of symmetry giving place to new diffraction spots characteristics of spinel phases. ${ }^{13}$ Our results suggest the formation of $\mathrm{InN}-\mathrm{zb}-\mathrm{In}_{2} \mathrm{O}_{3}$ metastable alloys with the aging process and this compound explain the continuous geometric phase transformation between the $\mathrm{InN}-\mathrm{w}$ and $\mathrm{In}_{2} \mathrm{O}_{3}$ phases. These kinds of alloys are described for the case of $\mathrm{AlO}_{x} \mathrm{~N}_{y}$, which form fcc spinel stable alloys cell commercially available in high quality optical components. ${ }^{29}$ In the case of indium, several authors have identified the presence of oxynitride phases with oxygen contents up to $30 \%$, although they are not structurally characterized. ${ }^{22,30,31}$ At any case, the presence of amorphous oxynitrides and hydroxides formed on $\mathrm{InN}$ and originated from atmospheric exposure is not appreciable. ${ }^{32}$ Finally, our results suppose a limitation in the applicability and storage of noncovered $\mathrm{InN}$ nanostructures devices as sensors or photodetectors. ${ }^{6,733}$ We have showed that $\mathrm{InN}$ nanostructures suffer an accelerated aging process compared to the $\mathrm{GaN}$ capped ones and this process must imply a change in their optical and electronic properties. In this sense, InN films modified by formation of an artificial thin surface oxide layer show changes in the electron mobility and the carrier sheet density where a partial depletion of electrons in the near surface region caused by the passivation of the surface donors is observed. ${ }^{33}$ A shift of the electron density distribution peak from the surface toward the bulk InN occurs that have to modify its potentiometric responses. Further work is in progress to map the localization of the different phases inside the QDs and to measure the temporal progression of the aging process.

\section{CONCLUSIONS}

In summary, the natural aging process of InN QDs under ambient conditions was studied. The comparison between two 36-months-aged samples with and without $\mathrm{GaN}$ capping layer showed structural changes regarding the original $\mathrm{InN}$ wurtzite phase. Thus, the $\mathrm{GaN}$ capping layer preserves the InN QDs from the atmospheric exposure and both wurtzite phases remain unchanged. On the contrary, uncapped QDs form a cover layer of cubic phases where the $\operatorname{In}_{2} \mathrm{O}_{3}$ is the main constituent at the end of the process. This process supposes the gradual transformation of the indium sublattice from hcp to fcc structures. This fact would explain the appearance of metastable InN-zb highly doped with oxygen observed as an intermediate phase between $\mathrm{InN}-\mathrm{w}$ and $\operatorname{In}_{2} \mathrm{O}_{3}$. Oxygen atoms are chemisorbed by substitution of nitrogen atoms that are desorbed and this process does not generate high strains because of the large concurrences among the interplanar spacing among all phases.

\section{ACKNOWLEDGMENTS}

Financial support from CICYT project MAT2007-60643, Junta de Andalucía project TEP383 (Spain) and SANDIE European Network of Excellence (NMP4-CT-2004500101 - Sixth Framework Program) is gratefully acknowledged.

${ }^{1}$ A. G. Bhuiyan, A. Hashimoto, and A. Yamamoto, J. Appl. Phys. 94, 2779 (2003).

${ }^{2}$ O. Ambacher, M. S. Brandt, R. Dimitrov, T. Metzger, M. Stutzmann, R. A. Fischer, A. Miehr, A. Bergmajer, and G. Dollinger, J. Vac. Sci. Technol. B 14, 3532 (1996).

${ }^{3}$ V. Yu. Davydov, A. A. Klochikhin, R. P. Seisyan, V. V. Emtsev, S. V. Ivanov, F. Bechstedt, J. Furthmüller, H. Harima, A. V. Mudryi, J. Aderhold, O. Semchinova, and J. Graul, Phys. Status Solidi B 229, R1 (2002).

${ }^{4}$ J. Wu, W. Walukiewicz, K. M. Yu, J. W. Ager III, E. E. Haller, H. Lu, W. Schaff, Y. Saito, and Y. Nanishi, Appl. Phys. Lett. 80, 3967 (2002).

${ }^{5}$ H. Lu, W. J. Schaff, and L. F. Eastman, J. Appl. Phys. 96, 3577 (2004).

${ }^{6}$ H. Lu, W. J. Schaff, L. F. Eastman, and C. E. Stutz, Appl. Phys. Lett. 82, 1736 (2003).

${ }^{7}$ Y.-S. Lu, C.-C. Huang, J. A. Yeh, C.-F. Chen, and S. Gwo, Appl. Phys. Lett. 91, 202109 (2007).

${ }^{8}$ W. C. Ke, C. P. Fu, C. Y. Chen, L. Lee, C. S. Ku, W. C. Chou, W. H. Chang, M. C. Lee, W. K. Chen, W. J. Lin, and Y. C. Chen, Appl. Phys. Lett. 88, 191913 (2006).

${ }^{9}$ S. Ruffenach, B. Maleyre, O. Briot, and B. Gil, Phys. Status Solidi C 2, 826 (2005)

${ }^{10}$ S. Ruffenach, O. Briot, M. Moret, and B. Gil, Appl. Phys. Lett. 90, 153102 (2007).

${ }^{11}$ C. Stampfl, C. G. Van de Walle, D. Vogel, P. Kruger, and J. Pollmann, Phys. Rev. B 61, R7846 (2000).

${ }^{12}$ A. G. Bhuiyan, K. Sugita, K. Kasashima, A. Hashimoto, A. Yamamoto, and V. Y. Davydov, Appl. Phys. Lett. 83, 4788 (2003).

${ }^{13}$ T. L. Tansley and C. P. Foley, J. Appl. Phys. 60, 2092 (1986).

${ }^{14}$ M. Wintrebert-Fouquet, K. S. A. Butcher, and Motlan, Phys. Status Solidi 
C 7, 2785 (2003)

${ }^{15}$ X. Xu, P. Specht, R. Armitage, J. C. Ho, E. R. Weber, and C. Kisielowski, Appl. Phys. Lett. 87, 092102 (2005).

${ }^{16}$ S. Y. Kwon, Z. Ren, Q. Sun, J. Han, Y.-W. Kim, E. Yoon, B. H. Kong, H. K. Cho, Il-J. Kim, and H. Cheong, Appl. Phys. Lett. 91, 234102 (2007).

${ }^{17}$ K. S. A. Butcher and T. L. Tansley, Superlattices Microstruct. 38, 1 (2005).

${ }^{18}$ J. G. Lozano, A. M. Sanchez, D. Gonzalez, R. Garcia, S. Ruffenach, and O. Briot, Appl. Phys. Lett. 88, 151913 (2006).

${ }^{19}$ J. G. Lozano, A. M. Sánchez, R. García, M. Herrera, N. D. Browning, S. Ruffenach, O. Briot, and D. González, Appl. Phys. Lett. 91, 071915 (2007).

${ }^{20}$ J. G. Lozano, F. M. Morales, R. García, V. Lebedev, Ch. Y. Wang, V. Cimalla, O. Ambacher, and D. González, Appl. Phys. Lett. 90, 091901 (2007).

${ }^{21}$ N. Nadaud, N. Lequeux, M. Nanot, J. Jove, and T. Roisnel, J. Solid State Chem. 135, 140 (1998).

${ }^{22}$ C. P. Foley and J. Lyngdal, J. Vac. Sci. Technol. A 5, 1708 (1987).

${ }^{23}$ Motlan, E. M. Goldys, and T. L. Tansley, J. Cryst. Growth 241, 165 (2002).
${ }^{24}$ E. Kurimoto, M. Hangyo, H. Harima, M. Yoshimoto, T. Yamaguchi, T. Araki, Y. Nanishi, and K. Kisoda, Appl. Phys. Lett. 84, 212 (2004).

${ }^{25}$ R. D. Jones and K. Rose, J. Phys. Chem. Solids 48, 587 (1987).

${ }^{26}$ B. R. Natarajan, A. H. Eltoukhy, J. E. Greene, and T. L. Barr, Thin Solid Films 69, 217 (1980).

${ }^{27}$ A. Zoroddu, F. Bernardini, V. Fiorentini, and P. Ruggerone, Phys. Rev. B 64, 045208 (2001)

${ }^{28}$ Y. Huang, H. Wang, Q. Sun, J. Chen, J. F. Wang, Y. T. Wang, and H. Yang, J. Cryst. Growth 275, 1073 (2005).

${ }^{29}$ P. Tabary and C. Servant, J. Appl. Crystallogr. 32, 253 (1999).

${ }^{30}$ K. L. Westra, R. P. W. Lawson, and M. J. Brett, J. Vac. Sci. Technol. A 6, 1730 (1988).

${ }^{31}$ S. M. Durbin, P. A. Anderson, A. Markwitz, and J. Kennedy, Thin Solid Films 515, 3736 (2007).

${ }^{32}$ K. S. A. Butcher, A. J. Fernandes, P. P.-T. Chen, M. Wintrebert-Fouquet, H. Timmers, S. K. Shrestha, H. Hirshy, R. M. Perks, and B. F. Usher, J. Appl. Phys. 101, 123702 (2007).

${ }^{33}$ V. Lebedev, V. M. Polyakov, S. Hauguth-Frank, V. Cimalla, Ch. Y. Wang, G. Ecke, F. Schwierz, A. Schober, J. G. Lozano, F. M. Morales, D. Gonzalez, and O. Ambacher, J. Appl. Phys. 103, 073715 (2008). 